\title{
Exploring the Role of Health Sector in the Prevention and Control of Cervical Cancer
}

\author{
Saurabh Ram Bihari Lal Shrivastava* and Prateek Saurabh Shrivastava \\ Department of Community Medicine, Shri Sathya Sai Medical College and Research Institute, Kancheepuram, India
}

\section{EDITORIAL}

Cervical cancer has been acknowledged as one of the major public health concerns, especially in the low-and middle-income nations [1]. The available global recent estimates suggest that cervical cancer alone accounts for the deaths of 0.3 million women, of which in excess of $85 \%$ have been reported in low resource settings of the world [2]. In other words, it has been estimated that every 2 minutes, one woman dies of cervical cancer across the globe and it is a matter of great concern as we already have direct interventions to prevent and treat the condition [2]. This clearly suggests the need of the intensification of the prevention and control activities and the need to strengthen measures in the high-risk groups [1-3].

Even though, a wide range of factors together determines the outcome of the cancer, nevertheless the health care professionals play an indispensable and a crucial role in the prevention and control of the cancer [1,2]. As a matter of fact, the health sector not only assists in the widespread implementation of the immunization activities against Human Papilloma Virus, but also in the screening and treatment area [1,2]. Furthermore, the scope of the health sector in the strengthening and expansion of the health promotion activities in itself is worth mentioning [2]. In addition, the health sector plays a remarkable role in the delivery of the palliative care (viz. management of pain or other symptoms, social and spiritual needs of the women/family members) [2].

Moreover, it has been reported that 9 out of 10 women who die from cervical cancer have limited access to the prevention or screening or treatment modalities [2]. Amidst all these problems, it is important to understand that it remains one of those types of cancer, which can be prevented or treated, provided the condition is diagnosed in the initial stages and subsequently managed efficiently [1-3]. However, for this to happen, the first and foremost thing is to strengthen the surveillance activities, so that the program managers can formulate evidence-based policies and take suitable actions [1]. In an attempt to respond to this problem, the World Health Organization has developed a toolkit to assist nations in the collection and use of the data for the welfare of the women [4].

In addition, efforts should be taken to expand the reach of screening activities and cover all the eligible women [3,5]. Further, a significant financial investment should be made in the advocacy, communication and social mobilization activities for making the general population aware about the predisposing factors and the facilities available in the health care establishments [2-4]. Moreover, measures have to be taken to expand the reach of immunization services and the treatment options [1,2]. Thus, strengthening of all the components is required to reduce the magnitude of the disease and the attributed deaths [1-4].

In conclusion, the role of the health care personnel and the health sector in the prevention and control of the cervical cancer is critical, as the disease often affects women living in lowresource settings and thus the onus to reach them and provide them with the desired services lies on the health professionals.

\section{REFERENCES}

1. Shrivastava SR, Shrivastava PS, Ramasamy J. Targeting cervical cancer in low and middle income nations: Necessity of a comprehensive approach. Ann Trop Med Public Health. 2017;10(5):1363-1364.

2. Cervical cancer resources for health professionals. World Health Organization. 2019.

3. Shrivastava SR, Shrivastava PS, Ramasamy J. Encouraging and expanding screening activities for cervical cancer in low-resource settings. Ann Trop Med Public Health. 2017;10(5): 1121-1122.

4. New toolkit to improve collection and use of data in cervical cancer programmes. World Health Organization. 2019.

5. Shrivastava SR, Shrivastava PS, Ramasamy J. Screening of cervical cancer: Barriers and facilitators. Iran J Cancer Prev. 2013;6: 177-178.

Correspondence to: Saurabh Ram Bihari Lal Shrivastava, Assistant Professor, Department of Community Medicine, Shri Sathya Sai Medical College and Research Institute, Kancheepuram, India, Tel: 919884227224; E-mail: drshrishri2008@gmail.com

Received: February 18, 2019, Accepted: February 19, 2019, Published: February 26, 2019

Citation: Shrivastava SRB, Shrivastava PS (2019) Exploring the Role of Health Sector in the Prevention and Control of Cervical Cancer. Biol Med (Aligarh) 11:e130. doi:10.35248/0974-8369.19.11.e130.

Copyright: (C) 2019 Shrivastava SRB, et al. This is an open-access article distributed under the terms of the Creative Commons Attribution License, which permits unrestricted use, distribution, and reproduction in any medium, provided the original author and source are credited. 